\title{
DETERMINATION OF THE OPTIMAL BACKORDER LEVEL FOR A LOT- SIZE REORDER POINT INVENTORY SYSTEM WITH BACKORDER PARAMETER
}

\author{
F. Owu ${ }^{1, *}$ and R. Edokpia ${ }^{2}$ \\ 1, 2, Department of Production Engineering, Univ. OF Benin, Benin City, Edo State, NIGERIA \\ Email addresses: ${ }^{1}$ festek1028@gmail.com, ${ }^{2}$ ralphedokpia@yahoo.com
}

\begin{abstract}
This paper attempts to investigate the existence of an optimal backorder level that will minimize the expected total inventory cost of a regular $(R, Q)$ lot-size reorder point system that is associated with backorder effect and establish the allowable backorder levels. To achieve this, the expected order cycle cost function of the lot-size reorder point system with backorder effect is optimized to determine the optimal backorder parameter. Numerical results presented showed that an optimal backorder level of 8 units exist where the expected order cycle cost is minimum with a value N19,036,000. Furthermore between the backorder level of 0 and 8 units, the order cycle cost decreases from $\$ 19,105,000$ to $\$ 19,036,000$. Thereby defining the range of the allowable backorder levels.
\end{abstract}

Key words: Backordered Level, Backorder Effect, Cycle Stock, Stock-Out and Backordered Demand.

\section{INTRODUCTION}

The lost- size-Reader point system of stock replenishment is a continuous review policy that defines a reorder point based on demand distribution during lead time, so that a lot size of a fixed order quantity $\mathrm{Q}$ which is often an economic order quantity (EOQ) is placed as soon as the inventory position reaches the reorder point, $\mathrm{R}$ [1]. Single delivery or regular ordering inventory models that allows for complete backordering requires that the total excess demand at the end of an order cycle (the time frame between the receipt of two consecutive regular orders) be backordered and satisfied at the commencement of the next order cycle [1 - 3]. The satisfaction of the backordered excess demand in an order cycle results in a reduction in the cycle stock (the available stock to meet demand within normal time period) of such an order cycle which is referred to as backorder effect in this study. This reduction in the cycle stock further increase the chances of higher values of excess demand at the end of the order cycle, if the prevailing demand is sustained.

The focus of previous studies is how to determine the number of units shorts at the end of the order cycle to be backordered and how to replenish the cycle stock of an order cycle where backordered excess demand was satisfied to minimize the expected cost and the stock-out level [4 - 6].

However, not all units of backordered excess demand can optimize the expected inventory cost of an operating regular ordering policy if backordering is allowed $[1,7,8]$.

Secondly, there is a range of backorder values for the policy with backorder effect that defines the allowable backorder level. The highest value in that range is the maximum or optimal value of backorder, since the expected inventory cost beyond this point starts increasing.

In this paper, an optimal backorder level which is the allowable maximum backorder level is determined for a lot-size reorder point inventory system with backorder effect. The optimal backorder level will help to determine the point of minimum cost with the use of the policy and establish a range of allowable backorder for the policy with a decreasing expected cost. 


\section{NOTATIONS}

The following notation where used in the sequel. The following notations will be adopted in development of the proposed model.

$\mu=$ The mean regular lead time demand rate

$\gamma=$ The mean demand rate per unit time

$\tau_{1}=$ The regular lead time

$l=$ Inventory rate

$l_{b}=$ The backorder level at the beginning of an order

$$
\text { cycle } l_{b}=1,2,3 \ldots l_{m}
$$

$R_{b}=$ The adjusted regular reorder point for an order

cycle with backorder effect

$\rho=$ The unit shortage cost per unit of item stock out at the end of a cycle

$C=$ Variable ordering cost per unit of the regular order quantity

$\mathrm{F}(\mathrm{R})$ : = Probability that lead time demand is less than or equal to the regular reorder point

$F\left(x_{L}\right)=$ The distribution function at $X_{L}$

$f\left(x_{L}\right)=$ The probability density function p.d.f of $X_{L}$

$G_{b}\left(l_{b}\right)=$ The expected regular order cycle cost for the regular ordering policy only with backorder effect

$h=$ Holding cost per unit per unit time

$l_{m}=$ The maximum backorder level allowable within an order cycle. $l_{m}=R *$

$l_{b}^{*}=$ The level of backorder that minimize the expected regular order cycle cost with back order effect

$K_{1}=$ Set-up or fixed ordering cost per regular order cycle

$S_{s}=$ The safety stock per regular order cycle without backorder effect

$\bar{S}_{s}=$ The safety stock for regular order cycle with backorder effect

$X=$ The annual demand rate, a random variable

$x=\mathrm{A}$ value of $\mathrm{X}$ i.e a realization on $\mathrm{X}$
$X_{L}=$ The Lead time demand, a random variable

$x_{L}=$ A value of $X_{L}$

$\mathrm{P}(\mathrm{R})$ : = The probability that lead time demand is greater than or equal to $\mathrm{R}$

$Q=$ The regular order quantity

$Q^{*}=$ The optimal regular order quantity.

$R=$ The regular reorder point

$R^{*}=$ The optimal regular reorder point

$t=$ Time

$\mathrm{T}=$ The regular order cycle length; a random variable.

$T_{b}=$ The expected total inventory cost per unit time for the regular order policy only with backorder effect

LTCP = Low Tension Concrete pole

$\mathrm{EOQ}=$ Economic Order Quantity

\section{ASSUMPTIONS}

1. The maximum allowable backorder level $l_{m}$ is equal to the optimal reorder level $R^{*}$.

2. The expected order cycle cost of the lot-size reorder point system with backorder effect is to have been formulated already following the approximation method of the cost formulation.

3. All optimal policy parameters besides that of the optimal backorder level are have been determined already.

4. The demand rate per annum (X) is discrete and follows a Poisson process and is approximated by a continuous process within lead time for convenience of computation.

\section{MODEL DEVELOPMENT}

Figure 1 shows the inventory realization process of an order cycle replenished with a lot-size reorder point system with backorder effect. In the policy operation, the starting inventory of the order cycle is reduced to $\left(Q^{*}-l_{b}\right)$ from $Q^{*}$ due to the satisfaction of the backordered excess demand $l_{b}$. It is expected for the optimal or the minimum allowable backorder value $l_{b}^{*}$ to be determined, such that $\mathrm{l}_{\mathrm{b}} \leq \mathrm{l}_{\mathrm{b}}$ * are the allowable backorder values. 


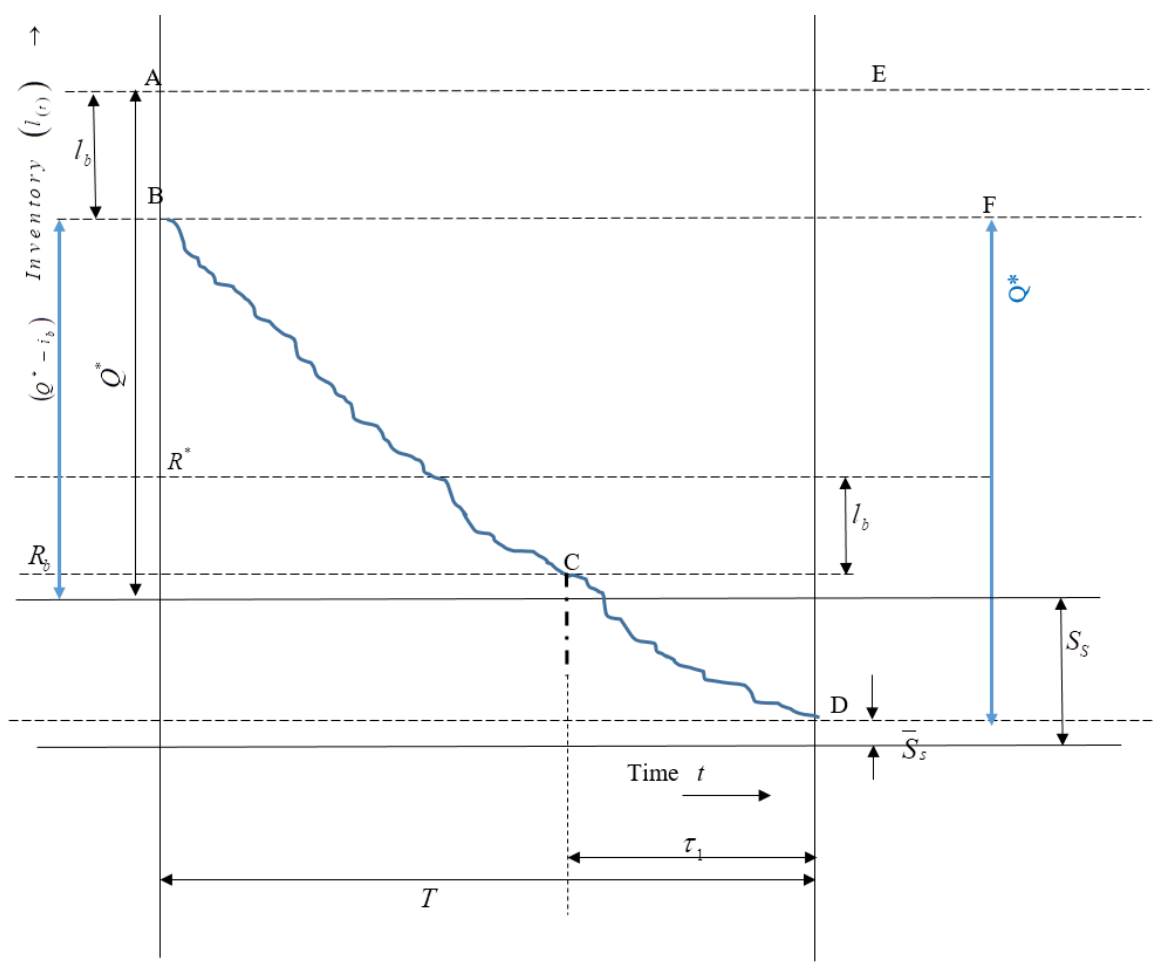

Figure 1: Inventory process for the restructured regular ordering policy for a Lot - size reorder point system with backorder effect.

\section{DETERMINATION OF THE OPTIMAL BACKORDER LEVEL $\left(l_{b}^{*}\right)$}

The order cycle cost of a lot-size reorder point system formulated alongside the approximation method stated in [9] is restructured by the introduction of a backorder parameter in this paper and stated in equation (1) as follows;

$$
\begin{aligned}
G_{b}\left(l_{b}\right)=\left(C Q^{*}+\right. & \left.K_{1}\right)+h\left[\frac{Q^{*}-3 l_{b}}{2}+R^{*}-\gamma \tau_{1}\right] \\
& +\rho \int_{\left(R^{*}-l_{b}\right)}^{\infty}\left[x_{L}\right. \\
& \left.-\left(R^{*}-l_{b}\right)\right] f\left(x_{L}\right) d x_{L}
\end{aligned}
$$

Where: $\quad\left(C Q^{*}+K_{1}\right), \quad h\left[\frac{Q^{*}-3 l_{b}}{2}+R^{*}-\gamma \tau_{1}\right] \quad$ and $+\rho \int_{\left(R^{*}-l_{b}\right)}^{\infty}\left[x_{L}-\left(R^{*}-l_{b}\right)\right] f\left(x_{L}\right) d x_{L}$ are the expected ordering, holding and shortage cost respectively.

The condition for achieving $l_{b}^{*}$ (optimal backorder level) is to differentiate $G_{b}\left(l_{b}\right)$ with respect to $l_{b}$ and set the differential equal to zero. The steps are as follows:

$$
\frac{d G_{b}\left(l_{b}\right)}{d l_{b}}=-3 \frac{h}{2}+\rho \int_{\left(R^{*}-l_{b}\right)}^{\infty} f\left(x_{L}\right) d x_{L}
$$

(from first principle and the product rule of differentiation).
But $f\left(x_{L}\right)=\frac{d F\left(x_{L}\right)}{d x_{L}}$ since it was assumed that the lead time demand is approximated by a continuous process.

Hence $\int f\left(x_{L}\right) d x_{L}=F\left(x_{L}\right)$

$$
\begin{aligned}
\Rightarrow \rho \int_{\left(R^{*}-l_{b}\right)}^{\infty} f\left(x_{L}\right) & d x_{L}=\rho\left[F\left(x_{L}\right)\right]_{R^{*}-l_{b}}^{\infty} \\
= & \rho\left[F(\infty)-F\left(R^{*}-l_{b}\right)\right] \\
& =\rho\left[1-F\left(R^{*}-l_{b}\right)\right]
\end{aligned}
$$

Since $F(\infty)=1$ [9]

$$
\Rightarrow \frac{d G_{b}\left(l_{b}\right)}{d l_{b}}=-3 \frac{h}{2}+\rho\left[1-F\left(R^{*}-l_{b}\right)\right]
$$

For optimality:

$$
\frac{d G_{b}\left(l_{b}\right)}{d l_{b}}=0
$$

Hence, equation (4)

$$
\rho\left[1-F\left(R^{*}-l_{b}^{*}\right)\right]=\frac{3 h}{2}
$$

But from probability
$1-F\left(R^{*}-l_{b}^{*}\right)=P\left(R^{*}-l_{b}^{*}\right)$ theory, 
$F\left(R^{*}-l_{b}^{*}\right)=P\left\{X_{L} \leq\left(R^{*}-l_{b}^{*}\right)\right\}$

$P\left(R^{*}-l_{b}^{*}\right)=P\left\{X_{L} \geq\left(R^{*}-l_{b}^{*}\right)\right\}$ and $l_{b}^{*}$ is the optimal backorder level.

Therefore,

$$
\begin{aligned}
& \rho\left[P\left(R^{*}-l_{b}^{*}\right)\right]=\frac{3 h}{2} \\
& P\left(R^{*}-l_{b}^{*}\right)=\frac{3 h}{2 \rho}
\end{aligned}
$$

Equation (8) can be expressed in terms of probability statement as;

$$
P\left(R^{*}-l_{b}^{*}\right)=P\left\{X_{L} \geq\left(R^{*}-l_{b}^{*}\right)=\frac{3 h}{2 \rho}\right\}
$$

Since $R^{*}$ is already known, the probability value corresponding to $\frac{3 h}{2 \rho}$ on the Poisson table under the mean lead time demand of $\boldsymbol{\mu}$ is subtracted from $R^{*}$ to obtain $l_{b}^{*}$ since demand is assumed to follow a Poisson process. For $l_{b}=l_{b}^{*}, G_{b}\left(l_{b}\right)$ will be minimum.

\section{FEATURES OF THE COST FUNCTION OF THE REGULAR ORDER ONLY WITH BACKORDER EFFECT}

Figure 2 shows the shape of the expected inventory cost per order cycle $G_{b}\left(l_{b}\right)$ for the regular ordering policy only with backorder effect against various backorder value $l_{b}$.

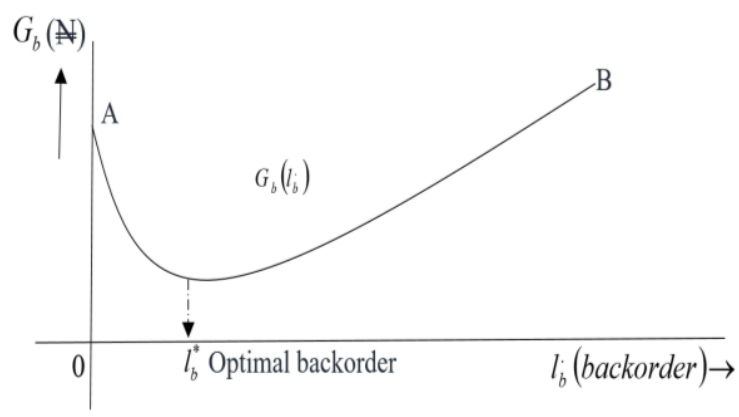

Figure 2: The curve of $G_{b}$ with respect to $l_{b}$ for the regular ordering policy only with backorder effect. The optimal backorder level is the point of minimize cost on the cost curve beyond this point the cost start increasing.

\section{COMPUTATIONAL RESULT}

The monthly demand of low tension concrete poles (LTCP) for seven years (2010 - 2016) obtained from a pole manufacturing firm is shown in Table 1.

The following information is given about the firm's inventory process.

$K_{1}=\mathrm{A} 200,000, C=A 90,000, \rho=A 170,000, h=$ A9,000, $\tau_{1}=1$ month

The value of the mean demand per year was estimated from Table 1 as $\gamma=865$ units/yr. $Q^{*}=198$ units, $R^{*}=93$ units and $l_{b}^{*}=8$ units.

Table 2 shows the expected order cycle cost for the regular ordering policy with backorder effect $G_{b}\left(l_{b}\right)$ for the considered backorder levels.

The lowest expected order cycle cost from the entries in Table 2 is N19,036,000 it occurs at a backorder level of 8 units, which is the optimal backorder level as determined. From backorder level of 0 to 8 units the expected order cycle cost decreases progressively. This range defines the allowable backorder level with the use of the policy with 8 units been the maximum allowable backorder level. Beyond this point, the expected order cycle cost starts increasing, hence requires a stock replenishment strategy to minimize the backorder effect.

The reason for the increasing cost is due to the higher number of units stock-out at the end of the order cycle with the increasing backorder level without stock replenishment.

The cost curve generated from plotting the various values of $G_{b}\left(l_{b}\right)$ against the corresponding values of $I_{b}$ in Table 2

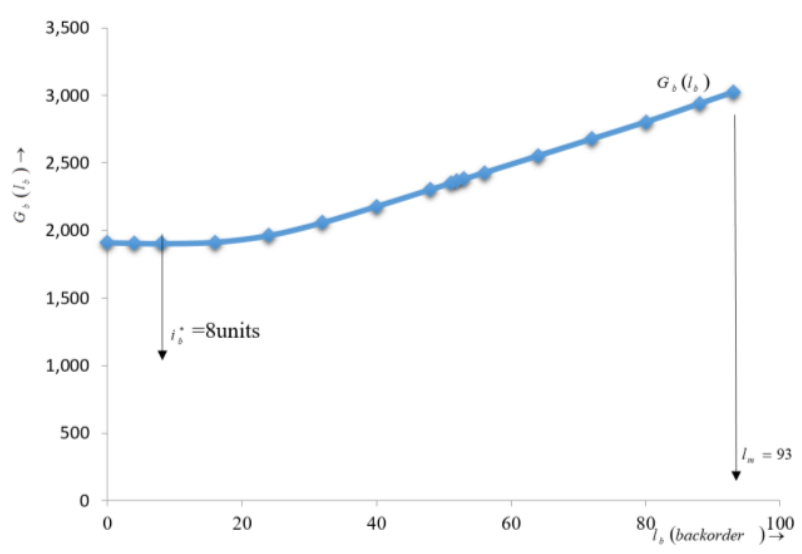

Figure 3: The curve of $G_{b}\left(l_{b}\right)$ against $I_{b}$ 
Table 1: Monthly Demand of Low Tension Concrete Electric Poles (LTCP) 2010 - 2016.

\begin{tabular}{ccccccccccccc}
\hline Year & Jan & Feb & Mar & Apr & May & Jun & Jul & Aug & Sept & Oct & Nov & Dec \\
\hline 2010 & 80 & 96 & 98 & 114 & 120 & 128 & 128 & 136 & 136 & 136 & 144 & 148 \\
2011 & 100 & 104 & 90 & 62 & 55 & 55 & 44 & 40 & 39 & 42 & 50 & 54 \\
2012 & 52 & 52 & 40 & 32 & 28 & 37 & 43 & 50 & 56 & 56 & 60 & 63 \\
2013 & 40 & 35 & 42 & 38 & 34 & 47 & 59 & 60 & 67 & 78 & 78 & 80 \\
2014 & 71 & 73 & 60 & 60 & 60 & 55 & 48 & 53 & 58 & 69 & 78 & 88 \\
2015 & 95 & 112 & 121 & 125 & 130 & 130 & 132 & 136 & 140 & 125 & 108 & 108 \\
2016 & 60 & 60 & 54 & 51 & 50 & 48 & 45 & 30 & 48 & 55 & 61 & 70
\end{tabular}

Source: Demand history from store department of O and O Technical Company, Kilometer 6 Benin Sapele Road, Benin City, Edo State, Nigeria.

Table 2: Different Expected Order Cycle Cost for the Regular Ordering Policy Only with Backorder Effect with Increasing Backorder Level

\begin{tabular}{cc}
\hline $\begin{array}{c}\text { Backorder values } \\
\operatorname{lb} \text { (unit) }\end{array}$ & $\begin{array}{c}\text { Expected Order Cycle Costs } \\
\text { for the Regular Ordering } \\
\text { Policy } G_{b}\left(l_{b}\right) N \times 10^{4}\end{array}$ \\
\hline 0 & $1,910.5$ \\
4 & $1,906.1$ \\
8 & $1,903.6$ \\
16 & $1,913.7$ \\
24 & $1,963.7$ \\
32 & $2,059.7$ \\
40 & $2,179.4$ \\
48 & $2,304.2$ \\
51 & $2,351.3$ \\
52 & $2,366.8$ \\
53 & $2,382.5$ \\
56 & $2,429.4$ \\
64 & $2,554.6$ \\
72 & $2,679.8$ \\
80 & 2,805 \\
88 & 2,941 \\
93 & 3,026 \\
\hline
\end{tabular}

\section{CONCLUSION}

An optimal backorder level has been determined for a lot-size reorder point system in this study. It was shown that the expected order cycle cost for the operating policy at this level of backorder is minimum. Furthermore, results showed that a range of backorder levels exist where even without stock replenishment that could attract extra cost, the operating policy cost decreases progressively. This characteristic property of the developed model makes it more attractive to use at the allowable range of backorders in terms of cost effectiveness. In the application of the Lot-size reorder point system to inventory control where complete backordering is allowed, it may not be necessary to replenish all backorder excess demand if such backorder demand are within the allowable range. Also the optimal backorder level should not be exceeded in the use of the policy for cost effectiveness.

\section{REFERENCES}

[1] Noblesse, A.M., Boute, R.N., Lambrecht, M.R. and Houdt, V.B. "Lot sizing and lead time decisions in production/inventory system", Preprint submitted to Elsevier. 2014.

[2] Sidney, B. and Paul, Z. "Inventory models with continuous stochastic demand", Annuals of Applied Probability, Vol. 1, 1991, pp $419-435$

[3] Jaksic. M, and Franson, J. "Optimal Inventory management Supply backordering", International Journal of Production Economic, Vol. 159, 2015, pp $254-264$.

[4] Liang-Yuh, O. and Hung-Chi, C. "The Variable Lead Time Stochastic Inventory Model with a Fuzzy Backorder Rate", Journal of the Operations Research of Japan, Vol. 44, number 1, 2001, M.

[5] Bhowmick, J. and Samanta, G.P. "Optimal inventory policies for imperfect inventory with price dependent stochastic demand and partially back logged shortages", Yugoslav Journal of Operations Research, vol. 22, 2012, pp. 199-223.

[6] Ren-Qian, Z., Yan-Liang, W., Wi-Guo, F. and Wen-Hui, Z. "Inventory model with partial backordering when backordered customers delay purchase after stock-out", Restoration Mathematical Problems in Engineering, vol. 2016, article ID 6425403.

[7] Moinzadeh, K. and Nahmias, S. "A Continuous Review Model for an Inventory System with two Supply Mode", Management Science, Vo. 34, 1988, pp. $761-773$.

[8] Johansen, S.G. and Thorstenson, A. "An Inventory Model with Poisson Demand and Emergency Orders", International Journal of Production Economics, Vol. 56-57, 1998, pp. $275-289$. 
[9] Nahmias, S. Production and Operations Analysis, McGraw Hill International 2009, ${ }^{\text {th }}$ edition.

[10] Chuanwen, D., Sandr, T. and Kai, H. "An inventory control model for modal split transport: A tailored base-surge approach", European Journal of Operational Research, Vol. 264, Number 1, 2018, pp 89-105.

[11] Chiang, C. "An order expediting policy for Continuous Review Systems with Manufacturing Lead Time", European Journal of Operational Research, Vol. 203 2010, Pp. 526-531.

[12] Arrow, K.J., Harris, T. and Jacob, M. "Optimal Inventory Policy", Econometrical, Vol. 19, Number 3, 1951, pp $250-272$.

[13] Frederick, S. and Gerald, J. Introduction to Operation Research, McGraw - Hill, New York, 1995, Sixth edition.

[14] Heijden, M.C. and Kok, T. "Estimating stock levels in periodic review inventory system",
Journal of operation Research Letters, Vol. 22, 1998, pp. 79-182

[15]Dohi, T., Kaw, N. and Osaki, S. "Continuous review cyclic inventory models with emergency order", Journal of the Operations Research, Vol. 38 Number 2, 1995

[16] Caplin, A.S. and Leahy, J. "Economic theory and the wood of practice: a celebration of the $(S, s)$ model", The Journal of Economic Perspective, vol. 24, Number 1, 2010, pp. 183 - 202.

[17] Iwu, C.H., Ogbonna, J.C., Jude O. and Onuma, G.K. "Application of inventory model in determining stock control in an organization", American Journal of Applied Mathematics and Statistics, vol 2, Number 5, 2014, pp. 307 - 317.

[18] Moon, I. and Choi, S. "A note on lead time and distributed assumptions in continuous review inventory models", Computers and Operations Research, Vol 25, 1998, pp 1007 - 1012 